\title{
DIFFERENTIAL RATES OF CHANGE IN CONSONANT AND VOWEL SYSTEMS
}

\author{
STEVEN MORAN $^{* 1}$ and ANNEMARIE VERKERK ${ }^{2}$ \\ *Corresponding Author: steven.moran@uzh.ch \\ ${ }^{1}$ University of Zurich \\ ${ }^{2}$ Max Planck Institute for the Science of Human History
}

Consonants and vowels are processed differently and they seem to have distinct neural representations (Caramazza et al. 2000). Böe et al. (2017) insist that vowel-like systems must be inferred to the last common ancestor of Baboons and humans, 25mya. Unlike vowels, however, consonants appear to be a later innovation in the communication systems of Hominids. Primates, including chimpanzees and orangutans, employ a repertoire of voiceless calls (so-called raspberries), which show homology with voiceless consonants (Lameira et al. 2014). During the course of human evolution, smaller orofacial cavities, increased neuro-cognitive abilities, and more precise motor control of the articulators led to greater phonetic variation, particularly among consonants, which have become phonologized in many ways in different language families. In comparison to vowels, there are over three times as many consonant phonemes in the world's languages. Their number and diversity ranges greatly, from 6 in Rotokas to over 90 in !Xu (Maddieson 1984); compare vowel systems which range in size from 2 to 14 . Why are there are so many more consonants in the world's languages?

The answer to this question is complex, with factors involving a need for increased number of lexical contrasts in order to accommodate a growing vocabulary throughout the evolution of language, and the greater possibility for consonants rather than vowels to increase the number of contrastive sounds in a language through secondary articulations. Two strands of evidence support this conclusion. First, comparing a database of proto-language reconstructions (Marsico et al, accepted; $\mathrm{n}=100$ ) with modern languages in UPSID (Maddieson 1984), Marsico (1999) notes an increase in the number of consonants in modern 
phonological inventories (even though there are no great differences between reconstructed and synchronic inventories). Second, in a large sample of phonological inventories described with a rich distinctive feature set (Moran, 2012; $\mathrm{n}=1672$ ), consonants are more often reported as marginal or borrowed than vowels (Moran et al, 2014). Both observations are in line with the need to increase vocabulary through the expansion of speech sound inventories via both vertical and horizontal transmission of languages.

Here we test whether six languages families (Arawakan (language sample $\mathrm{n}=38$ ), Austronesian (83), Bantu (114), Indo-European (58), PamaNyungan (134), and Tupi-Guarani (30); references to phylogenetic tree sets below) show larger rates of change for consonant inventory size as compared to vowel inventory size using phylogenetic comparative methods. Our results suggest that within the reconstructable timescale of language families in our sample, rates of change are in fact larger for consonants in some families, but not all. Ancestral state estimates of vowel and consonant inventory sizes are generally closer to the mean of the range rather than expert reconstructions of proto-languages, which warrants a closer evaluation using directional models of feature change. We also compare the fit of evolutionary models for continuous and discrete features to see which best accounts for phonological change.
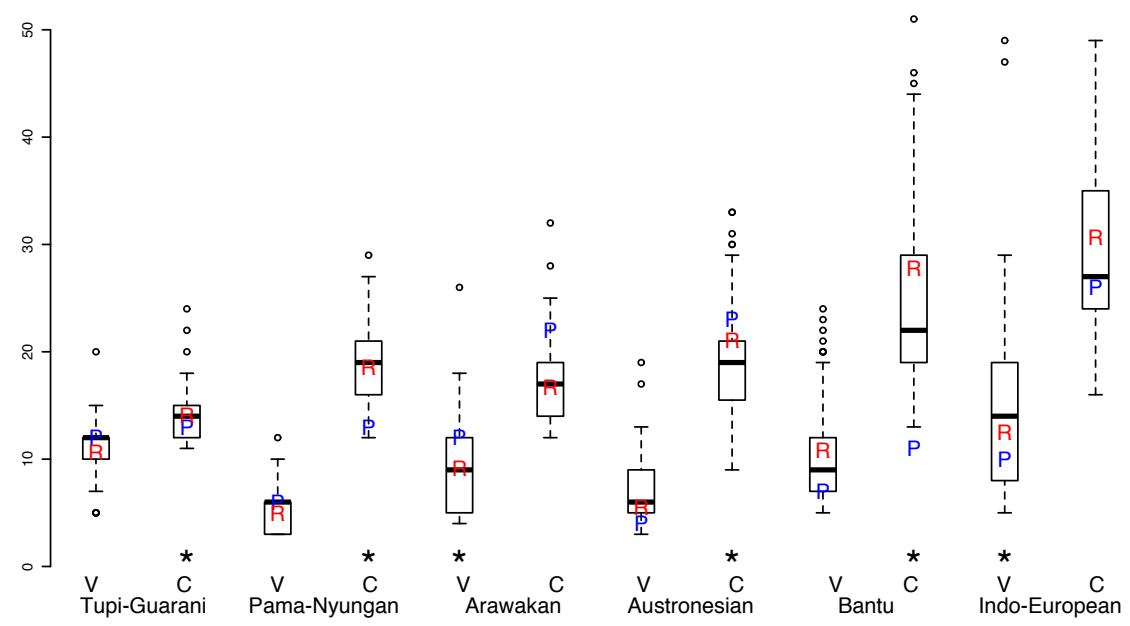

Figure 1: Box plots of the ranges of vowel and consonant inventory size in the language samples used for phylogenetic ancestral state estimations. P gives proto-language reconstruction from Marsico (1999). R gives ancestral state estimation. * indicates whether the rate of change of vowels or consonants is faster. 


\section{References}

Böe L.-J., Berthommier F., Legou T., Captier G., Kemp C., Sawallis T.R., Becker, Y., Rey, A., \& Fagot, J. (2017). Evidence of a Vocalic Proto-System in the Baboon (Papio papio) Suggests Pre-Hominin Speech Precursors. PLoS ONE 12(1): e0169321.

Caramazza, A., Chialant, D., Capasso, R., \& Miceli, G. (2000). Separable processing of consonants and vowels. Nature, 403(6768), 428.

Lameira, A. R., Maddieson, I., \& Zuberbühler, K. (2014). Primate feedstock for the evolution of consonants. Trends in Cognitive Sciences, 18(2), 60-62.

Maddieson, I. (1984). Patterns of Sounds. Cambridge University Press.

Marsico, E. (1999). What can a database of proto-languages tell us about the last 10,000 years of sound changes? In Proceedings of the XIVth International Congress of Phonetic Sciences (pp. 1-7).

Marsico, E., Flavier, S., Verkerk, A., \& Moran, S. (Accepted). BDPROTO: A Database of Phonological Inventories from Ancient and Reconstructed Languages. To appear in Proceedings of the 11th Language Resources and Evaluation Conference (LREC).

Moran, S. (2012). Phonetics Information Base and Lexicon. PhD thesis. University of Washington.

Moran, S., McCloy, D., \& Wright, R. (Eds.) (2014). PHOIBLE Online. Leipzig: Max Planck Institute for Evolutionary Anthropology. See: https://github.com/phoible/dev

\section{References for phylogenetic tree sets mentioned in abstract:}

Bouckaert, R., Lemey, P., Dunn, M., Greenhill, S. J., Alekseyenko, A. V., Drummond, A. J., Gray, R. D., Suchard, M. A. \& Atkinson, Q. D. (2012). Mapping the origins and expansion of the Indo-European language family. Science, 337, 957-960.

Bowern, C. \& Atkinson, Q. D. (2012). Computational phylogenetics and the internal structure of Pama-Nyungan. Language, 88(4), 817-845.

Gray, R. D., Drummond, A. J. \& Greenhill, S. J. (2009). Language phylogenies reveal expansion pulses and pauses in Pacific settlement. Science, 323, 479483.

Grollemund, R., Branford, S., Bostoen, K., Meade, A., Venditti, C. \& Pagel, M. (2015). Bantu expansion shows that habitat alters the route and pace of human dispersals. Proceedings of the National Academy of Sciences, $112(43)$, 13296-13301. 
Michael, L., Chousou-Polydouri, N., Bartolomei, K., Donnelly, E., Wauters, V., Meira, S. \& O'Hagan, Z. (2015). A Bayesian phylogenetic classification of Tupí-Guaraní. LIAMES, 15(2), 193-221.

Walker, R. S. \& Ribeiro, L. A. (2011). Bayesian phylogeography of the Arawak expansion in lowland South America. Proceedings of the Royal Society B, $278,2562-2567$. 